Grand Valley State University

ScholarWorks@GVSU

2005

\title{
An Interview with lan Browde Director of Strategy and Business Development, Enterprise Solutions Division, Nokia, Inc.
}

Carol M. Sanchez

Grand Valley State University, sanchezc@gvsu.edu

Follow this and additional works at: https://scholarworks.gvsu.edu/mgt_articles

Part of the Business Administration, Management, and Operations Commons

\section{ScholarWorks Citation}

Sanchez, Carol M., "An Interview with lan Browde Director of Strategy and Business Development, Enterprise Solutions Division, Nokia, Inc." (2005). Peer Reviewed Articles. 44.

https://scholarworks.gvsu.edu/mgt_articles/44

This Article is brought to you for free and open access by the Management Department at ScholarWorks@GVSU. It has been accepted for inclusion in Peer Reviewed Articles by an authorized administrator of ScholarWorks@GVSU.

For more information, please contact scholarworks@gvsu.edu. 


\section{Expert Opinion on Diverse ASSET Management Interview with Ian Browde}

\section{Published in Journal of Information Privacy and Security, 2005}

Interviewer, Carol Sánchez (CS), Associate Professor, Seidman College of Business, Grand Valley State University.

Interviewee, Ian Browde (IB), Director of Strategy and Business Development, Enterprise Solutions Division, Nokia, Inc.

\section{CS - You've developed an idea that you call Diverse ASSET Management, which you say is a new way to achieve disciplined sustainability of global business. What does that mean?}

IB - Whew! I was hoping you'd start off with an easy one $(-)$. The simplest way to understand my background thinking is to breakdown the phrase into its components. First let's ask why sustainability? In my view many businesses, especially, and ironically, large public ones do not have a sustainability orientation. Sustainability is about durability, longevity and endurance. It is about lasting for a long, long time.

Sustainability is not an idea, rather, it is a natural phenomenon. All one has to do is look around at nature and the sustainability orientation is clear, the oceans have it, trees and rocks and many species have it. It is programmed into the genetic code. Of course there are species that don't manifest it and when they don't they die out. For instance, some elephants instead of just eating the leaves from the trees in their environment actually uproot the trees. This shortsightedness places them in a precarious, unsustainable situation. Businesses that only manage for the short term are not sustainability oriented. They cut corners in their relationships with their customers, the quality of their products and services and their employees. They think that growth is all that counts and bigger, more, higher and such are the best ways of conceptualizing how to be in the market place. None of those is a sustainability word so their thinking is generally actually extinction oriented. Ironic, isn't it.

Now we should turn to ask why disciplined? Disciplined is intended to evoke the notion of training and practice over time to acquire a skill and a knowledge base as well as the atmosphere of order and self-control. Discipline does not happen accidentally it is intentional and it requires constant practice. In fact the practice required to learn discipline must itself be disciplined too. In business, discipline requires order, focus, rigor, prioritization and, often, courage. Even those areas where discipline appears counter-intuitive, it is a vital ingredient of success. For example innovation and creativity could be thought of as areas where discipline inhibits and yet those who engage in those pursuits will attest that the opposite in largely true. So my idea of disciplined sustainability in global business is about companies committing to being sustainable and continually refining their ability through regular practice. It requires a shift in thinking about everything and, more importantly, every relationship in that context. From the way the phone is answered to how and when customers are engaged in the product and service 
development, marketing and sales processes to how they manage their finances, the analyst community and their shareholder expectations.

\section{CS - What IS Diverse ASSET Management? Can you briefly explain it, and give our readers a taste of it?}

IB - Diverse ASSET Management is a heuristic-model for managing global companies, and I would argue that it is useful for managing any company. By heuristic-model I mean it is model to learn, use and practice, and not one to just read, take a few pointers from and forget about. It is intended to be the meta-filter through which all opportunities, problems, challenges and threats are viewed, analyzed and assessed.

So, Diverse ASSET Management consists of 4 fundamental assumptions and 6 keystone principles.

By "fundamental assumption," I mean an assumption that we all agree is so basic to business, contextually, that it is like a law or axiom and comparable to laws in other disciplines like physics with the law of gravity or the earth revolving around the sun, etc. These fundamental assumptions are: (1) Sustainability is the basis for success in business, (2) Business is relationships, (3) All relationships are asymmetric and (4) People are the most valuable, appreciating asset that a business has.

By "keystone principle," I mean a principle that we all agree is so important that without it a business will fail. These six principles are: (1) Diversity as a business strategy; (2) Adaptability; (3) Simplicity; (4) Social Capital; (5) Ethics and (6) Trust. It is worth noting that the last five principles form the acronym ASSET which is intended to evoke the notion that people are an asset, an appreciating asset in fact, that must be nurtured and treated with respect, care and, dare we say this in business, love? $\odot$.

\section{CS - What compelled you to start thinking about this?}

IB - The main driver I suppose was my innate desire to make a contribution to the survival of humanity as a species on this planet. I know it sounds like a grandiose vision, and I prefer to think of it as grand. When I look around at almost everything we humans do politically, economically, academically, socially, organizationally, it seems that we are intent on either rendering ourselves extinct or ensuring only the survival of a select few. To my mind, organized religion, ideology and government have failed in providing the structures necessary for humanity to survive, i.e., be sustainable, let alone thrive. Therefore I decided that the power and responsibility now resides with business and if businesses cannot effectively create contexts in which humanity can sustain itself then we are concerned, sooner than later, to go the way of the dinosaurs and the Roman and Ottoman empires. In looking at how business is meeting its obligations in this regard I became increasingly disillusioned since with a few exceptions all that seems to matter is more not better, bigger not appropriate, me not us or only us not all of us and finally us not the whole system of which we are a part. So I created a system, which can hopefully serve as a useful model for people to practice disciplined sustainability in the way they 
lead and manage in global business. If my model does not suit everyone then at least I hope it serves to promote other ideas of how to practice disciplined sustainability so $\mathrm{m}$ business can lead us out of the current state of darkness, apathy, depression, cynicism, exclusion and drudgery into a state of light, engagement, hope, humility, inclusion and fun.

\section{CS - How is Diverse ASSET Management different from other ways of managing companies?}

IB - Wow, you don't make it easy do you :). Rather than attempt to differentiate it from other ways of managing, both in theory and in practice, I will explain what I think are the fundamental differences. There are three areas of significant differentiation. The first is how this approach thinks about and relates to change. In my opinion change is always context, not content. So, in the business and organizational context, while people do cause change to occur they are always functioning inside of that change. People are the current; change is the ocean.

The second major difference between Diverse ASSET Management and other approaches to managing companies is that is assumes people as the most valuable asset that an organization has, rather than a resource to be exploited for its performance. It is about treating people as an asset to be stewarded over time, as a valuable asset that can appreciate in value given the appropriate nutrients and care. The third key distinction is that Diverse ASSET Management is intended to serve as an individual exercise platform, a practice environment that can potentially be used by each and every person in the company, and not merely a theory to be read or an upper management rallying call.

\section{CS - How does someone apply your idea of Diverse ASSET Management?}

IB - In theory this may be easy to answer, but in practice it is probably the hardest. One would first read the theory, and then think about it as a metaphor through which all business questions and issues will be filtered. So, each person begins by choosing a metaphor for exercise or training with which they are familiar. For example, if you are a tennis player, you might think ball machine or tennis wall. If baseball is your field, think of a batting cage. Weight trainers might think of a Nautilus machine or a stationary bike. Golfers would think of a driving range. Yoga practitioners would think of a mat and blocks. Think of what you work on when you use your practice platform of choice. Then think of Diverse ASSET Management as the same kind of platform. Instead of developing your muscles by pushing against resistance weights, develop your ideas and solutions by pushing them through the Diverse ASSET model. This will exercise your ability to manage your business, and will focus on purposefully connecting people to fulfill a vision, implement a strategy and achieve goals and objectives. Like an exercise platform, basic guidelines for usage should be followed, but each individual should use it in his or her own way. It becomes a personal and customizable practice environment, yet focused on the broad goals of the company at large.

\section{CS - How can we teach it to managers and our students, who are future managers?}


IB - The most honest answer I can give is I don't know. I have some ideas, but I hope that those who teach and those who manage others will figure out the best ways and share them with others and me. If this were to go according to my vision, it would become a movement that would enable change, not only among businesses, but within the very fabric of society. It would enable business to play the role of spiritual and pragmatic leader in the world.

Not to escape the question though, I offer these few suggestions:

We can create simple thought exercises for students and managers that allow them to play with the model part by part. For example, we present an exercise about creating a product or service, or one that involves a business problem. People think about it, talk about it, exercise it through the lens of diversity, and we see what emerges. Then we push the same exercise through the adaptability lens, then through the simplicity lens, and so on. What I believe we will notice is how easily we tend to slip back into our comfort zone of previously held assumptions and biases. This is the equivalent of falling back into the way we held our club or bat or racket before we started our new way of practicing. We notice it, and then, making no jud gment about it, refit our hold to the new grip, the new frame of diversity, adaptability, simplicity, trust and the others.

Another possibility is to use a similar exercise or a simple business problem that needs resolution and then role-play to see how an executive would deal with it using the new frames. Then convene a role-play meeting of the executive's direct reports and produce a conversation where the model is used. It might be useful to name one or two people as "trainers" or "coaches" who will notice when people stop exercising with the model. They will encourage the role-play team to stay with the program, as a personal trainer or language instructor might do when the task becomes difficult.

A third way could be to have people write, alone or in a small group, a company communication about a specific issue or create an advertisement for a specific job opportunity using the model as the guide. This idea is excellent for exercising the principles of diversity and social capital as an emerging notion of business value. For example, if a company wants to ensure that both men and women apply for a position, what nuances must be included in an ad's wording? How does the company encourage older people, people of color, gay people or physically challenged people to apply? 